\title{
Relato de experiência: o acolhimento em grupo como uma estratégia para a integralidade ${ }^{1}$
}

\author{
Mariana P. Ruwer de Azambuja \\ Cinara Debastiani \\ Caroline Castanho Duarte \\ Fabiane Minozzo \\ Ana Celina de Soura
}

\begin{abstract}
Resumo
Desejando ampliar a escuta aos usuários de uma Unidade Básica de Saúde, criou-se o "Acolhimento em Grupo", um espaço semelhante a um grupo de sala de espera, com foco em uma concepção ampliada de saúde. Tem como objetivo a construção de conhecimentos na coletividade e o fortalecimento do usuário como protagonista, fundamentando-se na concepção de educação popular, processos grupais e análise institucional. Os temas abordados foram funcionamento e qualidade dos serviços de saúde, aspectos de trabalho, reforma psiquiátrica, controle social e mobilização popular. Observamos como resultados a possibilidade do serviço refletir sobre sua organização e conceito de saúde, utilidade desta prática no processo de territorialização e maior aproximação entre profissionais e usuários. Apontamos como desafios a inclusão de mais profissionais na atividade, o desgaste emocional provocado naqueles que a realizam e a intersetorialidade.

Palabras-chave: Acolhimento; Sistema Único de Saúde (SUS/BR); Coletividade; Integralidade.
\end{abstract}

\section{Experience account: The "welcome in group" as a strategy to comprehensiveness}

\begin{abstract}
Desiring to extend the listening to the users in the actions from a Primary Care Unit, it was created the "Welcome in Group", a space alike to a "waiting room", which focuses on a health extended conception. It has as a main goal the construction of knowledge based on collectivism, in search of strengthening the user as a main character in the Welfare State System's (SUS/BR) actions, grounded on popular educational concepts, group processes and institutional analysis. The themes that were dealt with come as it follows health operation and quality, work aspects, psychiatric reform, social control and popular mobilization. As results the possibility of work reflecting on its organization and concept of health, the useful point of this practice on territorial process, better and bigger approach among professionals and users. Challenges to be thought about inclusion of more professionals in the activity, emotional stress caused on those who work in this area and intersectorial practice.

Keywords: Welcome; Only Welfare State System (SUS/BR); Collectivism; Comprehensiveness.
\end{abstract}

\section{Introdução}

Este é o relato de uma experiência desenvolvida por uma equipe multiprofissional da Residência Integrada em Saúde (RIS), ênfase Atenção Básica em Saúde Coletiva, no Centro de Saúde-Escola Murialdo (CSEM), Porto Alegre, RS. Em 2005, a equipe de residentes da Unidade Básica de Saúde VI (UBS VI) tomou como principal preocupação a reorganização dos fluxos e serviços, tendo como ponto de partida o acolhimento. Segundo Silva Júnior e Mascarenhas (2005), este pode ser entendido como um dos conceitos que se articula ao princípio da integralidade, podendo ser pensado em três dimensões:

\section{${ }^{2}$ Endereço para correspondência:}

Residência Universitária Lloyd Braga - Rua Prof. Carlos Lloyd Braga, s/no - quarto 219 - 4715-319 - Braga - Portugal Telefones: 00 (XX) 351253250651 - 00 (XX) 351936616741

E-mail: mariruwer@ig.com.br
Como postura [...], a atitude, por parte dos profissionais [...], de receber, escutar e tratar humanizadamente os usuários e suas demandas [e de incorporar] a escuta e a conversa [...] como importantes instrumentos de trabalho [...] como técnica, instrumentaliza a geração de procedimentos e ações organizadas [que] facilitam o atendimento na escuta, na análise, na discriminação do risco e na oferta acordada de soluções ou alternativas aos problemas demandados [...] com isso, rearticula-se 0 serviço. (Silva Júnior \& Mascarenhas, 2005, p. 243246 , grifos nossos)

Inicialmente, alterou-se o modo de distribuição das consultas médicas diárias. Até então, um cartaz informava o número de consultas disponibilizadas no dia. 
Apesar deste ter sido um pedido da população, considerou-se que era uma forma de "expulsar" os usuários que, ao visualizarem a fila existente e o número afixado no cartaz, acabavam por ir embora. Havia uma demanda reprimida que não chegava a ser conhecida. Reforçava-se a lógica médico-centrada, pois a população e, por vezes, a equipe - não vislumbrava a possibilidade de atendimento por outro profissional que não o médico. $\mathrm{O}$ cartaz foi extinguido e se percebeu uma maior concentração de pessoas na entrada da UBS. A fim de organizar a "fila" e otimizar o trabalho do acolhedor, implantou-se a distribuição de fichas coloridas conforme o tipo de demanda. Este processo foi desenvolvido ao longo do ano, envolvendo reuniões de equipe e seminários teóricos, buscando sensibilizar os demais profissionais. Andou lentamente, com apoio e/ou descontentamentos. Buscou-se trabalhar com a idéia do acolhimento como postura desenvolvida por todos os profissionais, envolvendo desde o vigilante, a auxiliar de higienização e de enfermagem até os preceptores e residentes, procurando um maior vínculo com a comunidade.

Modificar os padrões da relação profissionais de saúde/clientela, objetivando ampliar os coeficientes de vinculo deles com pessoas portadoras de problemas concretos dentro de um certo contexto existencial. Essa seria a pedra de toque de qualquer projeto que pretendesse mudar os modos de atenção. (Campos, 1997, p. 265)

Nessas reflexões, percebeu-se que "demanda espontânea" pouco tinha de voluntária. Houve necessidade de escutar a "voz" da comunidade e ampliar o espaço de escuta dentro da UBS. Fala-se em ampliação do espaço porque este já potencialmente existia nos vários grupos realizados e no acolhimento individual. Ainda assim, percebia-se a necessidade de um espaço que não dependesse de um tema já instituído, como geralmente ocorre nos grupos, e que não estivesse vinculado a um procedimento ou ação do serviço, como ocorre no acolhimento individual e nos encontros que antecedem consultas ou entrega de medicamentos.

\section{O acolhimento em grupo na prática}

Foi inspirado em uma atividade semelhante desenvolvida na UBS VIII do CSEM e em idéias como as de Hennington (2005), que também trabalhou com o acolhimento em uma perspectiva grupal:

[..] surge uma nova instância terapêutica, expande-se a forma de acolbimento, buscando-se ainda o delineamento de novos caminhos de interação trabalhador/aluno-usuário e resposta aos problemas de saúde e, quem sabe, a constituição de um verdadeiro espaço reflexivo, crítico e de autogestão. (Hennington, 2005, p. 261)

$\mathrm{Na}$ prática, configura-se como um espaço semelhante a um "grupo de sala de espera", com o foco em uma concepção ampliada de saúde. Tem como objetivo a construção de conhecimentos na coletividade em busca do fortalecimento do usuário como protagonista das ações do serviço de saúde, fundamentando-se nos pressupostos da educação popular, processos grupais e análise institucional. Neste relato, são discutidos os oito primeiros encontros, desenvolvidos como experiências piloto. Eram coordenados por duas facilitadoras e registrados por uma relatora, com duração aproximada de uma hora. Ocorriam concomitantemente ao acolhimento individual, enquanto os usuários aguardavam seus atendimentos. Buscava-se que fosse um espaço autoregulado, tendo como ponto de partida a apresentação da equipe e do objetivo dessa atividade. A partir da fala inicial ("estamos aqui para ouvi-los"), muitos ficavam em silêncio, sendo necessário estimular a participação com a apresentação dos presentes. Algumas vezes, acabou-se por dirigir o encontro para questões como a origem dos usuários e, para os não-naturais da cidade, o motivo de terem vindo para Porto Alegre. Percebeu-se que a maioria dos que procuravam a UBS VI havia migrado em busca de trabalho e melhores condições de vida ou de tratamentos de saúde. Questões relativas ao adoecimento no/por trabalho apareceram como um dos pontos centrais para a busca por atendimento na UBS, tanto em virtude do estresse laboral (aposentadorias especiais, tratamento) quanto pelas dificuldades advindas de sua falta (depressão, empobrecimento, dificuldade de acesso a outros cuidados). Esta constatação tornou clara a necessidade de promover uma maior articulação com a "rede" a fim de desenvolver atividades intersetoriais (por exemplo, com instituições de inserção social e formação profissional). "Rede" pode ser entendida como o conjunto das várias secretarias que oferecem os serviços necessários para a conquista da saúde, bem como os serviços da comunidade (cursos, lazeres, esportes, escolas, igrejas etc.). Em ambos os casos, implica a responsabilidade dos profissionais em oferecer cuidados integrais e não o simples encaminhamento de referência e contra-referência. Sendo vista como um recurso terapêutico, potencializa a relação entre usuário e serviço de saúde.

Muitas vezes, vieram críticas quanto à qualidade dos serviços de saúde, grande tempo de espera pelas consultas, dificuldades de encaminhamento para especialistas e falta de medicamentos, entre outras. Para a equipe de acolhedora, era difícil não dar respostas "prontas". Mas, buscava-se lançar questionamentos, argumentos e esclarecimentos que os levassem à reflexão e 
às próprias conclusões. Houve também queixas sobre o descaso político e os poucos investimentos na região, defendendo a contratação de mais médicos e criação de novos postos de saúde. Novamente, buscava-se estimular a reflexão sobre quem seriam os "culpados", discutindo-se a participação política, a responsabilidade nas eleições de cargos públicos e a pouca participação da comunidade no controle social (apesar dos esforços da equipe de saúde, ainda não haviam sido eleitos os representantes do conselho local de saúde). Enfim, instigavam-se os coletivos a refletirem sobre sua participação, responsabilidade e autoria na mudança. Cabe destacar que a maioria não sabia o que é o controle social e tampouco tinha conhecimentos sobre os conselhos locais de saúde. As reuniões mensais que a UBS realizava com a comunidade eram vistas pelos usuários como espaços de mera reclamação, com pouca resolutividade. Alegavam não participar por causa do horário, por desconhecimento e por considerarem que "não daria em nada".

Dois acolhimentos em grupo foram "temáticos", alusivos ao dia Luta Antimanicomial (18 de maio). Discutiu-se o que é a loucura e a reforma psiquiátrica, surgindo, entre os usuários, o medo em relação ao louco, visto como aquele que perde a noção da realidade, que não controla a si mesmo, que vive como um "animal" (sujo, comendo restos, sem roupa). Como solução, apontavam a sua exclusão no Hospital Psiquiátrico. Questionou-se o que é loucura, ampliou-se a discussão sobre saúde mental e sobre o que é um tratamento em saúde mental. Enfatizouse o sujeito em sofrimento psíquico e a necessidade deste receber cuidados nas unidades básicas. Enfim, tentou-se ampliar as concepções de saúde mental e de cuidado.

O acolhimento tem sido discutido por diversos autores (Gomes \& Pinheiro, 2005; Hennington, 2005; Silva Júnior \& Mascarenhas, 2005) como uma estratégia de reorientação da assistência à saúde, buscando alterar a lógica do atual modelo tecnoassistencial com o objetivo de alcançar o princípio da universalidade. Sendo assim, tratase de um dispositivo que vai muito além da mera recepção do usuário.

\footnotetext{
É nesse chamado "espaço intercessor" que ocorrem o conflito, a possibilidade de mudança e do ato criativo, que permite superar as barreiras e dificuldades no atendimento das necessidades de saúde [...] deve ser considerado uma nova tecnologia de trabalho, situando-se no âmbito da denominada micropolítica do trabalho em saúde, em que o processo de trabalho torna-se espaço público, passivel de discussão coletiva e de reorientações, permitindo a efetiva autogestão de trabalhadores e construção da autonomia dos usuários. (Hennington, 2005, p. 260)
}

\section{Considerações finais}

Apesar dos muitos aspectos positivos, ainda existem desafios para a efetiva implantação do acolhimento em grupo, como a inclusão de mais profissionais, conseqüência do entendimento de o acolhimento ser responsabilidade da equipe. Somente assim se pode refletir e reordenar a lógica dos serviços tendo em vista um modelo que deixe de trabalhar com o atendimento à demanda espontânea, rompendo com o modelo curativo e assistencialista. Um obstáculo à integralidade foi a necessidade de maior articulação com a "rede" para o desenvolvimento de ações intersetoriais, sendo importante contar com a comunidade como parceira, numa lógica de co-gestão e co-responsabilização, por meio do estímulo ao controle social e à implantação do conselho local de saúde. Outro desafio foi a superação/minimização do desgaste emocional causado nos profissionais que realizam o acolhimento em grupo, provocado não só pela "pressão" exercida pela população na busca de respostas e resolutividade, como pelo enfrentamento do desconhecido, haja vista ser uma atividade sem uma estruturação prévia e auto-organizada. Nesse sentido, conquistou-se um momento de supervisão, semelhante aos núcleos interdisciplinares apresentados por Hennington (2005, p. 260).

Por fim, observam-se como produções positivas desta experiência piloto a possibilidade do serviço refletir sobre sua (re)organização, sua utilidade no processo de territorialização (maior conhecimento da comunidade), aproximação entre profissionais e usuários (vínculo), reflexão sobre o conceito de saúde de forma ampliada, desconstrução da lógica de não-participação popular (estímulo ao controle social) e a possibilidade de oferecer um cuidado à saúde pautado na integralidade. Dessa forma, o acolhimento em grupo consiste em uma atividade de promoção de saúde, pois incide na mudança da cultura sobre o que é saúde e seus cuidados. Através dele, ampliase a visão de que a UBS somente tem que oferecer cuidados curativos, médicos e imediatos e saúde passa a ser pensada como acesso a um trabalho digno, moradia, lazer, participação, ação, escuta, fala. Enfim, como cidadania.

\section{Notas}

1 Relato de experiência também apresentado por Azambuja; Debastiani; Duarte; Minozzo e Souza no II Fórum Gaúcho de Saúde Coletiva/I Fórum da Região Sul de Saúde Coletiva/I Fórum do Mercosul de Saúde Coletiva (Porto Alegre, RS, Brasil, outubro de 2005) e em Cidadania(s): Congresso Internacional sobre Discursos e Práticas (Porto, Portugal, julho de 2006). 


\section{Referências}

Campos, G. (1997). Subjetividade e administração de pessoal: considerações sobre os modos de gerenciar o trabalho em equipes de saúde. Em E. E. Merhy \& R. Onocko (Org.). Agir em saúde (pp. 229-266). São Paulo: Hucitec.

Gomes, M. \& Pinheiro, R. (2005). Acolhimento e vínculo: práticas de integralidade na gestão do cuidado em saúde em grandes centros urbanos. Interface (Botucatu), 9(17) [On line]. Disponível em: <www.scielo.br>. Acesso em: 18 jan. 2006.

Hennington, É. A. (2005). Acolhimento como prática interdisciplinar num programa de extensão universitária.
Cadernos de Saúde Pública. 1 [On line]. Disponível em: <www.scielo.br>. Acesso em: 18 jan. 2006.

Silva Júnior, A. G. \& Mascarenhas, M. T. (2005). Avaliação da atenção básica em saúde sob a ótica da integralidade: aspectos conceituais e metodológicos. Em R. Pinheiro \& R. Mattos (Org.). Cuidado: as fronteiras da integralidade (pp. 241-258). Rio de Janeiro: CEPESC; UERJ, ABRASCO.

Sobre as autoras:

Mariana Porto Ruwer de Azambuja: psicóloga e mestre em Psicologia Social pela PUCRS, ex-aluna da Residência Integrada em Saúde, ênfase Atenção Básica em Saúde Coletiva, doutoranda em Psicologia Social na Universidade do Minho, Portugal (com o apoio do Programa Alban, Programa de Bolsas de Alto Nível da União Européia para a América Latina).

Cinara Debastiani: assistente social, pós-graduada em Saúde Coletiva na ênfase Atenção Básica pela Escola de Saúde Pública do Rio Grande do Sul, mestranda em Serviço Social na Pontifícia Universidade Católica do Rio Grande do Sul (PUCRS).

Caroline Castanho Duarte: enfermeira (UEL/PR), residente do programa Residência Integrada em Saúde, ênfase Atenção Básica em Saúde Coletiva, da Escola de Saúde Pública do Rio Grande do Sul.

Fabiane Minozzo: psicóloga (UNISINOS), pós-graduada em Saúde Coletiva na ênfase Atenção Básica pela Escola de Saúde Pública do Rio Grande do Sul, consultora da Unesco para a Estratégia de Saúde da Família no Rio Grande do Sul.

Ana Celina Souza: enfermeira (UFRGS), residente do programa Residência Integrada em Saúde, ênfase Atenção Básica em Saúde Coletiva, da Escola de Saúde Pública do Rio Grande do Sul. 